\title{
CAMBIOS ELECTROCARDIOGRAFICOS Y REQUERIMIENTOS ANESTESICOS CON ISOFLURANO EN PROTOCOLO EXPERIMENTAL DE RATONES DE PESO NORMAL Y OBESOS
}

\author{
Araneda Ríos Felipe', Vera Meier Pablo \\ Médico Cirujano. Programa de Magister en Fisiopatología. Universidad de Chile. \\ Médico Cirujano en Programa de Formación de Postítulo en Anestesiología y Reanimación, Universidad de Chile.
}

Introducción: La sedación en modelos animales experimentales requiere técnica de anestesia y monitorizaciona adecuadas. Isoflurano ofrece sedacion minimamente invasiva. No hay descripciones en la literatura de su efecto cardiovascular y de los requerimientos anestésicos en ratones obesos.

Objetivo General: Estandarizar el uso de Isoflurano en ratones de peso normal y obesos, asegurando sedación y anestesia para monitorización, y evaluar presencia de alteraciones electrocardiograficas.

Material y Métodos: Sujetos: 10 Ratones alimentados con dieta regular y 10 ratones con dieta alta en grasas, desde las 2 semanas de vida, por 8 semanas.- Equipo: Maquina de Anestesia con vaporizador para Isoflurano, flujo de 1 lt/ min. Caja de inducción anestesica. Mascarilla de anestesia para sedación vía narinas. Ventilación espontánea.- Monitorización: Peso, ECG durante sedación, patron respiratorio, oxímetria de pulso, Respuesta a estimulo tactil con punta jeringa e inyección intraperitoneal de vehículo.- Registro: FC, Qt, QRS durante sedación, mediante progra- ma LabChart 8.0. Concentración de Isoflurano para sedoanalgesia efectiva a los 30 segundos de ingreso a caja de inducción, y concentración mínima de mantención, verificada por estimulo tactil y doloroso. - Análisis de Datos: Se compararon valores de FC, FR, y ECG con valores descritos en la literatura. Dosis Promedio inducción a los 30 segundos, dosis de mantención para estimulo tactil y para estimulo nociceptivo.

Resultados: FC basal en ratones obesos en menor a peso normal con Isoflurano, y QRS tiende a prolongarse con anestesia en ambos grupos. Sin alteración en resto de constantes electrocardiograficas. Sin alteración de mecánica ventilatoria, frecuencia respiratoria y oxímetria de pulso. En cuanto a requerimientos anestesicos:- Dosis Inducción $4 \%$ en 30 segundos en ambos grupos.Ratones Peso normal: 1,0-1,5\% Mantención. 2\% para analgesia a estimulo nociceptivo.- Ratones Obesos: 2,0-2,5\% Mantención. 2,5-3,0\% para analgesia a estimulo nociceptivo. Diferencias significativas entre grupos en peso promedio, FC promedio, y requerimientos anestesicos.

Conclusiones: Isoflurano provee anestesia $\mathrm{y}$

Tabla 1

\begin{tabular}{|lcccc|}
\hline & Peso Normal & Obesos & p & Valores Normales \\
Peso (grs) & 26,5 & 37,5 & $<0,01$ & 20 a 40 \\
Frecuencia Cardiaca (lpm) & $430( \pm 30)$ & $350( \pm 20)$ & $<0,01$ & 300 a 800 \\
Frecuencia Respiratoria (rpm) & $120( \pm 10)$ & $110( \pm 10)$ & ns & 100 a 200 \\
Oximetria Pulso (\%Sat $\left.\mathrm{O}_{2}\right)$ & $92( \pm 2)$ & $92( \pm 2)$ & ns & 90 a 94 \\
QRS (ms) & $70( \pm 5)$ & $65( \pm 10)$ & ns & 9 a 30 \\
QT (ms) & $94( \pm 6)$ & $92( \pm 10)$ & ns & 29 a 109 \\
Dosis Inducción Isoflurano a 30 & & $4 \%$ & $4 \%$ ns & $<0,05$ \\
Dosis Mantención Sedación & $1,0-1,5 \%$ & $2,0-2,5 \%$ & $<0,05$ & \\
Dosis Mantención Analgesia & $2,0-2,5 \%$ & $2,5-3,0 \%$ & & \\
\hline
\end{tabular}


analgesia segura, minimamente invasiva, y facilmente titulable en modelo experimental de raton. Otorga relativa estabilidad de parametros electrocardigraficos. Presentaria limitaciones para estudios donde se requiere estudio de velocidad de conducción intraventricular. Permite ajuste dinámico sedoanalgesia, y minimizar artefactos de registro, y disminuir tiempos requeridos para inducción y despertar, en comparación a otras alterativas usadas en este tipo de modelos (Ketamina/Xylacina, Pentobarbital). Menor FC en ratones obesos podría estar en contexto de dosis sedación necesaria, o cardiopatia de base; no queda claro con datos presentados. Trabajo en marco de proyecto de tesis de Magister de Fisiopatología: "Arritmogénesis en ratones alimentados con dieta rica en ácidos grasos saturados", derivado de proyecto FONDECYT N${ }^{\circ} 160704$. 